\title{
Microstructure Analysis and Measurement of Nonlinearity of Vapour Phase Reflowed Solder Joints
}

\author{
$\underline{\text { A. Pietriková }}{ }^{1)}$, P. Mach ${ }^{2)}$, J. Ďurišin ${ }^{1)}$, L. Livovský $^{1)}$ and J. Urbančík ${ }^{1}$ \\ ${ }^{1)}$ Faculty of Electrical Engineering and Informatics, Technical University of Kosice, Letna 9, 04200 Kosice, Slovakia \\ ${ }^{2)}$ Faculty of Electrical Engineering, CTU Prague, Prague, Czech Republic \\ alena.pietrikova@tuke.sk
}

\begin{abstract}
The goal of the study is to compare quality of lead-free vapour phase reflowed solder joints soldered on different printed circuit board $(P C B)$ surface finishes. The solder joints quality comparison is based on evaluation of microstructure development of the solder, solder/PCB pad interface and on the measurement of the solder joints nonlinearity of the current-voltage $(C-V)$ characteristics. The microstructure is evaluated before and after accelerated ageing.
\end{abstract}

\section{INTRODUCTION}

The big advantage of the heat transfer in vapour phase soldering (VPS) is the extremely efficient transfer of latent heat through the condensing vapour and uniform temperature distribution (Ball Grid Array - BGA package). The temperature of any saturated vapour cannot exceed the temperature of the boiling liquid $\left(\mathrm{SnAgCu}\right.$ alloys, $\left.230^{\circ} \mathrm{C}\right)$. Quality of the solder joint is considerably affected by its microstructure; particularly important is presence of the intermetallic compounds (IMCs). The reflow temperature profile, besides other factors, has strong influence on growth and thickness of the IMCs, especially reflow zone and rate of cooling. Ageing (accelerated ageing) also affects occurrence of the IMCs. The ageing causes increase of presence and coarsening of the IMCs, what has negative influence on strength, electrical properties (resistance) and lifetime of the joints.

\section{EXPERIMENTAL MATERIAL AND PROCESSING}

As experimental material were used 2 different lead-free KOKI solder pastes containing: a) ternary alloy $96.5 \mathrm{Sn} 3 \mathrm{Ag} 0.5 \mathrm{Cu}$ - SAC (melting point $217-218$ ${ }^{\circ} \mathrm{C}$, powder spherical particles size $20-38 \mu \mathrm{m}, 11.5 \%$ content of ROL0 flux type), b) quaternary alloy 90Sn3.5Ag0.5Bi6In - SABI (melting point 202-211 ${ }^{\circ} \mathrm{C}$, spherical particles size $20-38 \mu \mathrm{m}, 11.5 \%$ content of ROL1 flux type). There were also used four different PCB surface finishes (PCB conductive layer - $\mathrm{Cu}$ foil): Electroless Nickel/Immersion Gold ENIG, Hot Air Solder Leveling - HASL, Sn and $\mathrm{Cu}$ finish. Reflow soldering of the SAC (SABI) solder was realized in experimental VPS oven, reflow peak temperature was $230^{\circ} \mathrm{C}$ (Figure 1.).

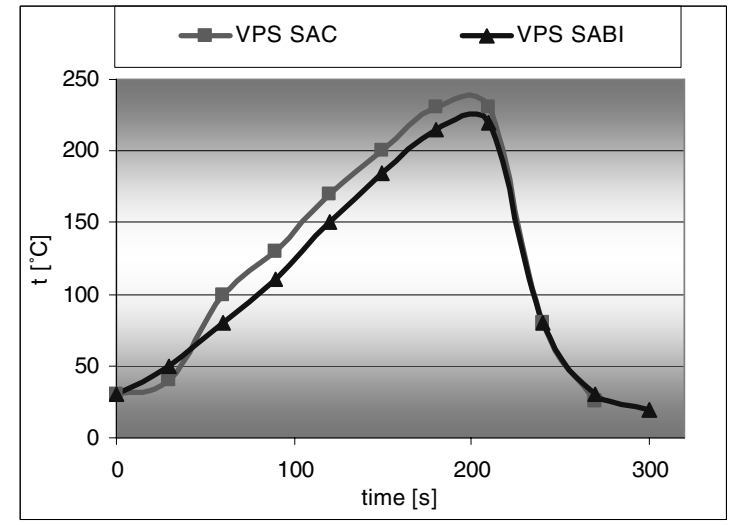

Figure 1. Reflow temperature profile.

Effect of the accelerated ageing was achieved by the solder joints exposure to standard conditions (temperature of $150^{\circ} \mathrm{C}$ ) according to norm MIL 883F, Method 1008.2. The ageing was performed in electronically controlled (temperature) conditioning chamber. 


\section{MiCROSTRUCTURE ANALYSIS MEASUREMENT OF NONLINEARITY}

AND

\subsection{Microstructure analysis}

Microstructure analysis was performed mainly because of the detection of the IMCs. Chemical composition of the IMCs and the detection of the residual stresses was specified by Philips X'Pert Pro $\mathrm{X}$-ray diffraction meter. Distribution, morphology, orientation, thickness, shape of the IMCs were observed and recorded by light microscope Olympus GX71 and JEOL 7000F scanning electron microscope (SEM).

Typical microstructure of both solder (SAC, SABI) alloys, before the ageing, shows that faster cooling (cca $\left.5^{\circ} \mathrm{C} / \mathrm{s}\right)$ creates finer dendrites and reduces presence of coarse IMCs. The $\mathrm{B}-\mathrm{Sn}$ dendrites are clearly outlined by interdendritic regions of eutectic microstructure, which are densely packed with large numbers of very fine compound particles (Figure 2.).

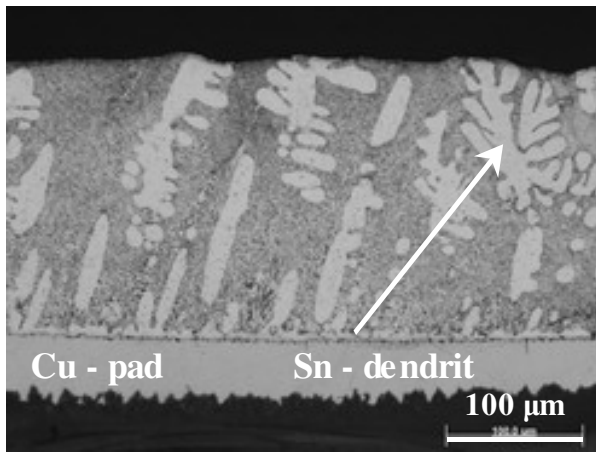

Figure 2. Microstructure of lead-free SAC solder.

Each solder alloy has a tendency for the primaryphase formation of $\mathrm{Cu}_{6} \mathrm{Sn}_{5}\left(\mathrm{Cu}_{3} \mathrm{Sn}\right.$ ) or $\mathrm{Ag}_{3} \mathrm{Sn}$ (Figure 3.). The microstructure consists of clearly defined $\mathrm{Sn}$ dendrites, some binary $\mathrm{Ag}_{3} \mathrm{Sn}$-Sn eutectic and ternary $\mathrm{Ag}_{3} \mathrm{Sn}-\mathrm{Cu}_{6} \mathrm{Sn}_{5}-\mathrm{Sn}$ eutectic. The compounds phases appear in the expected lamellar and fibrous forms. The solder joints show the precipitation of island-type particles $\left(\mathrm{Cu}_{6} \mathrm{Sn}_{5}\right)$ in the bulk solder matrix and evident formation of $\mathrm{Cu}_{3} \mathrm{Sn}$ (Figure 4.) near the solder-PCB $\mathrm{Cu}$ pad interface (except ENIG). Huge amount of the brittle IMCs contributes to decrease of plastic properties. Faster cooling $\left(4-5{ }^{\circ} \mathrm{C} / \mathrm{s}\right)$ of the solder joints is necessary due to the finer microstructure formation resulting in improved mechanical and electrical properties. Microstructure analysis shows that cooling rate holds over the thickness of the IMCs. Faster cooling produces a thickness of the IMCs thinner than $1 \mu \mathrm{m}$. In ENIG case, the Au dissolves and migrates into the solder alloy. This allows the formation of an IMC layer made of $\mathrm{Ni}_{3} \mathrm{Sn}_{4}$. The IMCs mean size is ordinal $\mu \mathrm{m}$.

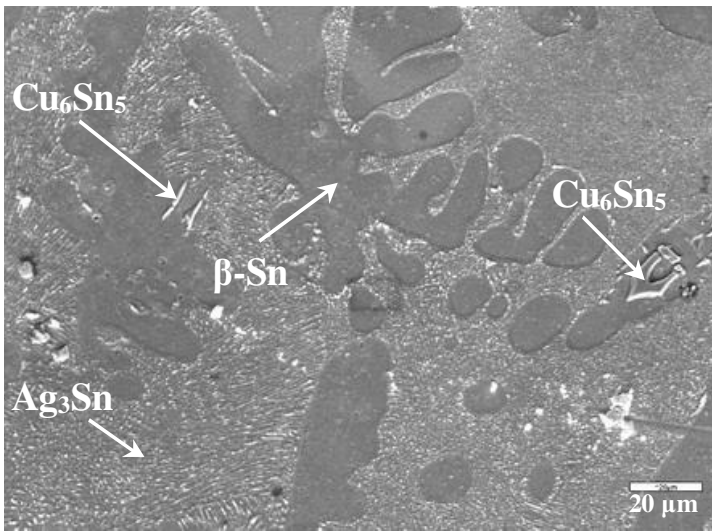

Figure 3. SEM microstructure of lead-free SAC solder.

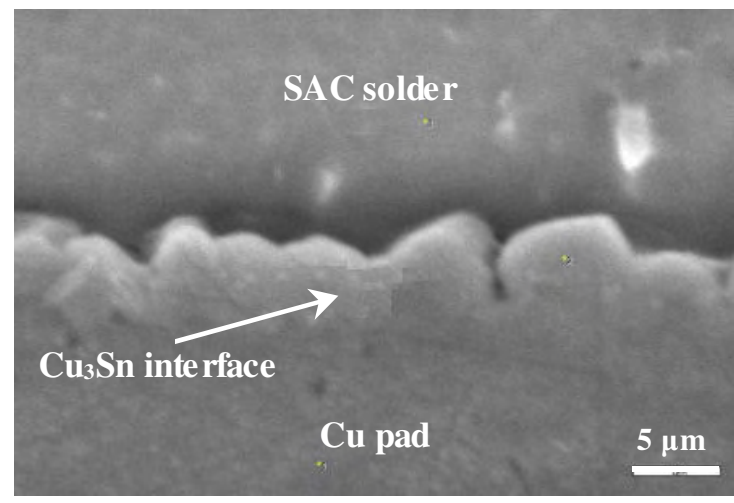

Figure 4. SEM microstructure of lead-free SAC solder.

Effect of ageing is in case of SAC solder very significant. Initially lamellar and fibrous $\mathrm{Ag}_{3} \mathrm{Sn}$ structure is broken up into particulate form. It is the first change noted in the as solidified microstructure. The Sn dendrites, as well as the binary and ternary eutectic regions, remain clearly defined. After the next ageing the Sn dendrite pattern is still well defined by the interdendritic eutectic structure, but some coarsening of the eutectic is occurred and growth of the larger particles is noted. The following ageing process causes the Sn dendrite pattern to fade. The substantial coarsening of the interdendritic eutectic is occurred. It appears that this coarsening of the eutectic is responsible for the $\mathrm{Sn}$ dendrite pattern becoming less distinct, since the outlines become more diffuse. The larger particles continue to grow. The formation of relatively large particles of the $\mathrm{Ag}_{3} \mathrm{Sn}$ phase, comparable to those seen for $\mathrm{Cu}_{6} \mathrm{Sn}_{5}$ occurs at much 
longer ageing times than those required for $\mathrm{Cu}_{6} \mathrm{Sn}_{5}$, because the diffusion rate for Ag, although still very fast compared with self diffusion in Sn, is much slower than that for $\mathrm{Cu}$. Owing to the larger concentration of $\mathrm{Ag}$ compared to that for $\mathrm{Cu}$ in volume of this SAC solder alloy and consequent larger number of $\mathrm{Ag}_{3} \mathrm{Sn}$ particles, the diffusion distance required to form relatively large particles of $\mathrm{Ag}_{3} \mathrm{Sn}$ is smaller than that for $\mathrm{Cu}$, resulting in significant coarsening of the $\mathrm{Ag}_{3} \mathrm{Sn}$ phase. These ageing caused changes are expected to influence the mechanical properties of the solder [1].

The X-ray diffraction is used for analysis of socalled residual stresses. The stresses exist in solder without application of external load (tensile, shear, pressure). The origin of these stresses is in way of the solder (solder paste) processing (temperature retraction, phase transformation, heterogeneous plastic deformation, etc.). The type of the residual stress depends on: "operation" distance (grain size), number of phases (type of crystal lattice, chemical composition) and dislocations or other defects. The origin of the residual stresses is: mechanical mechanical processing of the solder, thermal - nonuniform cooling after soldering, different coefficient of thermal expansion (CTE) of the various phases of the solder and the solder joint $(\beta-S n$, intermetallic compounds, PCB laminate, etc.), chemical - volume changes caused by chemical reactions - IMC formation, precipitation or phases transformation $(\beta$ Sn dendrites, Sn whiskers, IMC, etc.) [2]. The PCB and component surface finishes can result in significant differences of the residual stresses in surface layers of the soldered components.

The residual stresses exhibit in defects locations of crystal material and at the interface of different materials, e.g. at the interface of the IMC $\left(\mathrm{Cu}_{6} \mathrm{Sn}_{5}\right.$ hexagonal crystal lattice) and $\beta$-Sn (tetragonal crystal lattice). The X-ray diffraction analysis (Figure 5.) of the residual stresses lies in application of the Bragg's law. The residual stresses cause shift of interplanar dimension of single phases.

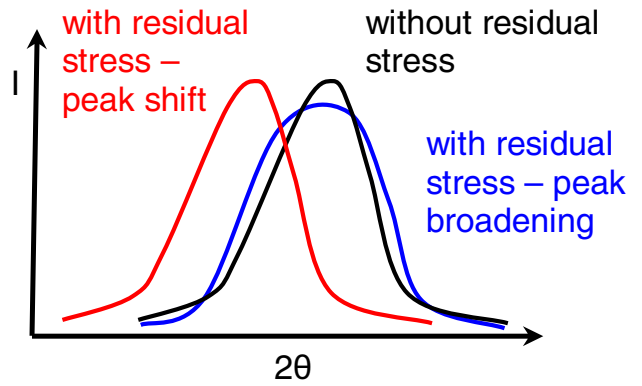

Figure 5. X-ray diffraction pattern of the residual stresses.

\subsection{Measurement of nonlinearity}

Measurement of nonlinearity of the $\mathrm{C}-\mathrm{V}$ characteristics lies in evaluation of intermodulation distortion (IMD). IMD is caused by nonlinear behavior of the signal processing being used. IMD is the result of two or more signals interacting in a nonlinear device to produce additional unwanted signals. These additional signals occur mainly in devices such as amplifiers and mixers, but to a lesser extent they also occur in passive devices such as those found in many transmission systems. Two interacting (input) signals $\mathrm{f}_{1}, \mathrm{f}_{2}$ will produce intermodulation products at the sum and difference of integer multiples $(\mathrm{n}, \mathrm{m})$ of the original frequencies. The most important is $3^{\text {rd }}$ order harmonics, which represents potential spurious signal. Higher order intermodulation products are generally less important because they have lower amplitudes and are more widely spaced [3]. The distortion was evaluated with spectral analyzer unit HP 8560E. The general assumption for $\mathrm{C}-\mathrm{V}$ measurement is that two tones are applied to a device under test - solder joint at frequencies of $f_{1}$ and $\mathrm{f}_{2}$ (IN1, IN2). The intermodulation products are described by the next equation:

$f=n \cdot f_{1}+m \cdot f_{2}$

where $n, m$ are integer multiples of the original input frequencies $f_{1}, f_{2}$.

The selected frequencies are: $\mathrm{f}_{1}=4,106 \mathrm{MHz}, \mathrm{n}$ $=1$, and $\mathrm{f}_{2}=150 \mathrm{kHz}, \mathrm{m}=2$. Then the final measured frequency is: $f=4,406 \mathrm{MHz}$. In the measurement was used power measurement equivalent to $1 \mathrm{~mW}-$ evaluation of nonlinearity in $\mathrm{dBm}$. For evaluation of the $3^{\text {rd }}$ order harmonics $U_{c}=U_{3}(\mathrm{n}+\mathrm{m}=3)$ can be used equation (2) or evaluation with noise index $N I$ (3): 
$U_{C}=224.1000 .10^{N I / 20} \quad[\mu \mathrm{V}]$

$N I=20 \cdot \log \frac{U_{C}}{U_{1}} \quad[\mathrm{dBm}]$

Table 1. Effect of surface finish on nonlinearity of the $\mathrm{C}-\mathrm{V}$ characteristics of SAC solder joints.

\begin{tabular}{l|c|c|c|c|c|l|}
\hline & \multicolumn{6}{|c|}{ NI [dBm] } \\
$\begin{array}{l}\text { Surface } \\
\text { finish }\end{array}$ & $\mathbf{1}$ & $\mathbf{2}$ & $\mathbf{3}$ & $\mathbf{4}$ & $\mathbf{5}$ & $\begin{array}{l}M E A \\
N\end{array}$ \\
\hline & -137 & -138 & -135 & -138 & -137 & $-\mathbf{- 1 3 7}$ \\
\hline & -138 & -139 & -137 & -137 & -138 & - \\
\hline & -137 & -137 & -136 & -137 & -138 & $-\mathbf{- 1 3 7}$ \\
\hline HASL & -144 & -145 & -143 & -143 & -145 & $\mathbf{- 1 4 4}$ \\
\hline
\end{tabular}

Table 2. Effect of surface finish on nonlinearity of the $\mathrm{C}-\mathrm{V}$ characteristics of SABI solder joints.

\begin{tabular}{|c|c|c|c|c|c|c|}
\hline & \multicolumn{6}{|c|}{ NI [dBm] } \\
\hline $\begin{array}{l}\text { Surfac } \\
\text { e }\end{array}$ & 1 & 2 & 3 & 4 & 5 & MEAN \\
\hline Euish & - & - & -139 & 139 & -138 & - \\
\hline Sn & - & - & -137 & 137 & -138 & - \\
\hline HASL & - & - & -137 & 138 & -137 & - \\
\hline ENIG & - & - & -145 & $14314 \$$ & & -144 \\
\hline
\end{tabular}

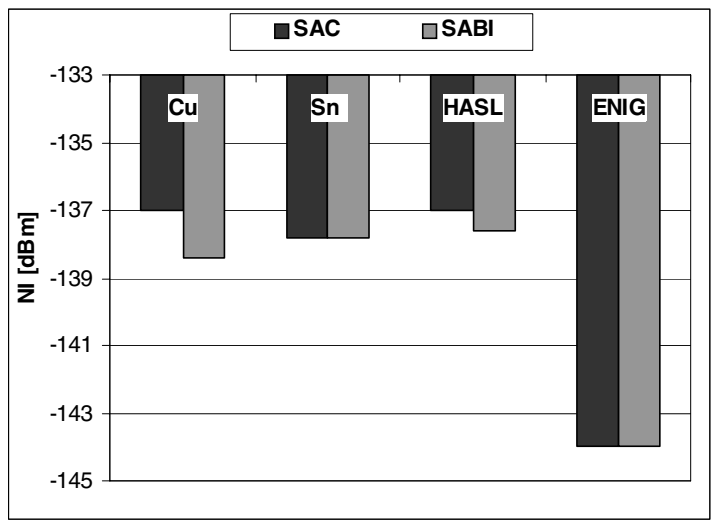

Figure 6. Evaluation of nonlinearity of the C-V characteristics of the surface finishes.

From the measurement it is significant that nonlinearity measurement as a quality determination of the solder joints is very hard to be acceptable for all types of surface finishes - Table 1 and Table 2. All measured values of NI are on the limit of the measuring tool. So the final mean results (Figure 6.) show only differences between ENIG and other types of the PCB surface finishes. Higher nonlinearity of $\mathrm{Cu}, \mathrm{Sn}$ and HASL surface finishes was measured. For ENIG surface finish the nonlinearity of solder joint is insignificant (conductive path: $\mathrm{NI} \cong-145 \mathrm{dBm}$ ). It means that the lowest nonlinearity was measured for ENIG PCB surface finish

\section{SUMMARY}

The microstructure analysis of the solders demonstrated significant presence of $\beta$-Sn dendrites, which are clearly outlined by interdendritic eutectic composed of the intermetallic compounds in a $\mathrm{Sn}$ matrix. With the ageing, the $\beta-S n$ dendrite pattern becomes progressively less distinct owing to coarsening of the $\mathrm{Cu}_{6} \mathrm{Sn}_{5}$ and $\mathrm{Ag}_{3} \mathrm{Sn}$ phases, which outline the dendrites. Coarsening of the $\mathrm{Ag}_{3} \mathrm{Sn}$ particles occurs more slowly because the diffusion rate of the $\mathrm{Ag}$ atoms is markedly slower than that of $\mathrm{Cu}$ [1]. The intermetallic compounds cause occurrence of the residual stresses, resulting in structural defects, negatively influencing properties of the solder joints. The ageing of electronic devices results in degradation of their quality parameters [4].

The measurement of nonlinearity of the $\mathrm{C}-\mathrm{V}$ characteristics of the solder joints showed, that ENIG PCB surface finish has the lowest nonlinearity compared to other PCB surface finishes. This fact contributes to less distortion of a signal being transmitted.

\section{ACKNOWLEDGMENTS}

This work was supported by the Slovak Grant Agency VEGA contracts 1/3167/06, Sk-Cz 0065-07, KEGA $3 / 6465 / 08$ as well as Lifelong Learning Programme1 AGR. n 07/0227 L/4116.

\section{REFERENCES}

[1] Snugovsky, D. D. Perovic, J. W. Rutter: "Experiments on the aging of $\mathrm{Sn}-\mathrm{Ag}-\mathrm{Cu}$ solder alloys", Powder Metallurgy, Vol. 48, No. 2, 2005, pp. 193-198.

[2] www.protoxrd.com, "X-ray Diffraction Residual Stress Measurement, an Introduction", 2006.

[3] A. Pietrikova, J. Bansky, J. Durisin: "Measurement of Nonlinearity of Lead-free Vapour Phase Reflowed Solder Joints", Acta Electrotecnica et Informatica, Vol. 7, No. 3, 2007, pp. 9-12, ISSN 1335-8243.

[4] J. Beran: "Metody uplatnovane v programoch spolahlivosti”, Spolehlivost 2003, Brno, International Conference Proceedings, 2003, pp. 29-34, ISBN 8085960-63-X. 